Scientia Agricola

http://dx.doi.org/10.1590/1678-992X-2015-0318

\title{
Performance of Holstein calves having free access to milk and dosed with
}

\section{Megasphaera elsdenii}

\author{
Mukengela Claude Muya ${ }^{*}$, Lourens Johannes Erasmus ${ }^{3}$, Kevin Miller ${ }^{2}$, Celine Aperce ${ }^{2}$, Florence Veronica Nherera ${ }^{1}$, Portia \\ Mamothaladi Moshidi ${ }^{1}$
}

${ }^{1}$ Agricultural Research Council-API, Private Bag X2 - Irene 0062 - Pretoria - South Africa.

${ }^{2}$ MS Biotec, 1300 Kaw Valley Road, Wamego, Kansas, KS 66547 - Wamego - USA.

3University of Pretoria, Private bag X20 - Hatfield 0028 -

Pretoria - South Africa.

${ }^{*}$ Corresponding author <MuyaM@arc.agric.za>

Edited by: Paulo Cesar Sentelhas

Received August 18, 2015

Accepted June 05, 2016
ABSTRACT: Megasphaera elsdenii converts lactate and glucose into butyrate, the main volatile fatty acid responsible of papillae development and may benefit calf performance. Twenty-six Holstein calves (BW $=34.5 \pm 1.65 \mathrm{~kg}$ ) were randomly assigned at birth to a control group (Meg0) and a group that received an oral dose of M. elsdenii NCIMB 41125 at $14 \mathrm{~d}$ of age (Meg14). Calves received colostrum for the first $3 \mathrm{~d}$ followed by free choice access to whole milk until weaning at $56 \mathrm{~d}$. From d 4 onward, starter and water were offered ad libitum. Intakes were measured daily and body weights (BW) weekly. Blood samples were collected on day 7, 21, 28, 42, and 56 for $\beta$-hydroxybutyrate (BHBA) analysis. Performance was measured for an additional $14 \mathrm{~d}$ post-weaning. Pre-weaning milk intake was lower $(p=0.010)$ and starter DMI (dry matter intake) greater ( $p=0.001$ ) for Meg14 than Meg0 calves. Total DMI, metabolisable energy (ME) intake and average daily gain (ADG) were similar $(p>0.05)$ for both groups, but Meg14 calves had greater weaning BW $(p=0.012)$ and feed efficiency $(p<0.029)$. The average BHBA between $d$ 21 and 56 was greater for Meg14 ( $p=0.03$ ) compared to Meg0 calves. After weaning, Meg14 calves had greater DMI $(p=0.027)$, ME intake $(p=0.023)$ and ADG $(p=0.002)$ and tended to have better feed efficiencies ( $p=0.07$ ) than Meg0 calves. Administering M. elsdenii NCIMB 41125 improved starter intake and feed efficiency, which was associated with high blood BHBA. Keywords: Beta-hydroxybutyrate, rumen development, weaning, probiotics

\section{Introduction}

The amount of milk consumed by young dairy calves influences gut development (Anderson et al., 1987) and determines intake of starter feed as well as health and growth of calves (Appleby et al., 2001). Studies to improve milk-feeding systems for dairy calves through ad libitum milk feeding have shown higher milk consumption and BW gain, with reduced starter intake, compared to restricted milk feeding (Appleby et al., 2001; Hammon et al., 2002; Jasper and Weary, 2002). Delayed solid feed intake because of ad libitum milk consumption during the pre-weaning period (Appleby et al., 2001; Hammon et al., 2002) results in delayed ruminal development with subsequent poor post-weaning performance (Baldwin et al., 2004) and poor welfare (Khan et al., 2007).

Rumen development is an important factor determining early solid feed intake and performance in cattle (Górka et al., 2009). Butyrate and propionate are the main volatile fatty acids (VFA) responsible for rumen epithelial and papillae development in the pre-weaned ruminant (Coverdale et al., 2004). Megasphaera elsdenii is thought to play a major role in production of branchedchain of VFA in the rumen (Wallace, 1986) and alter rumen fermentation in favour of propionate and butyrate as end products (Henning et al., 2010).

In a recent study, dosing M. elsdenii NCIMB 41125 to calves in restricted milk feeding system improved feed intake and rumen development, suggesting increased epithelium metabolism and improved absorption of di- gestive end products. These effects were associated with increasing ruminal butyrate concentration (Muya et al., 2015). Possibly M. elsdenii also plays a positive role in rumen development under condition where starter intake is suppressed due to ad lib or high volume milk feeding in accelerated growth-feeding systems. The objective of this study was to evaluate the influence of an oral dose of $M$. elsdenii NCIMB 41125 at 14 d of age on pre- and post-weaning intake, performance, and ruminal development of calves fed milk ad libitum in the morning and afternoon.

\section{Materials and Methods}

\section{Animals and treatments}

The experiment was conducted in Pretoria, South Africa (2553'54.1" S 28²' $01.6^{\prime \prime}$ E: 1526 m altitude). Twenty-six Holstein calves (BW $=34.5 \pm 1.65 \mathrm{~kg}$ ) were blocked based on order of birth and sex and randomly assigned at birth to one of the two treatments. The treatments were a control group, which did not receive $M$. elsdenii (Meg0) and a M. elsdenii group (Meg14), which received a 50-mL oral dose of $M$. elsdenii NCIMB 41125 $\left(10^{8} \mathrm{CFU} \mathrm{mL} \mathrm{m}^{-1}\right)$ at $14 \mathrm{~d}$ of age. Calves were fed colostrum for the first $3 \mathrm{~d}$ of life followed by free choice access to whole milk (CP: $4 \%$; Fat: $4 \%$; Lactose: $5 \%$ ) during feedings at $08 \mathrm{~h} 00$ and $14 \mathrm{~h} 00$. Milk was offered in a 5 $\mathrm{L}$ bucket and if the calf consumed all of the $5 \mathrm{~L}$, it was immediately refilled until voluntary intake ceased. From d 52 until weaning (d 56), milk intake was limited to $4 \mathrm{~L} \mathrm{~d}^{-1}$, offered once daily at $08 \mathrm{~h} 00$. A commercial calf 
starter feed (19\% CP, $4 \%$ fat, $13 \mathrm{MJ} \mathrm{kg}^{-1}$ of DM ME) was offered ad libitum starting at d 4 of age until weaning at $\mathrm{d} 56$. Fresh water was available ad lib throughout the study.

\section{Measurements and sample collection}

Daily calf starter, milk and water consumption of each calf were measured throughout the experiment. Starter was offered at $08 \mathrm{~h} 00$, with starter intake recorded daily for each calf. Calves were initially offered 250 $\mathrm{g}$ of starter, and the remaining feed was weighed back at each delivery time. Amounts of offered feed starter were increased by $250 \mathrm{~g}$ increments when calves refused less than $50 \mathrm{~g}$ of feed. Calves were weighed at birth and at 7-day intervals throughout the experiment before AM milk and starter feeding. Average daily gain was calculated from weekly weight gain. Average BW gain, total DM intake, feed efficiency ( $\mathrm{kg}$ BW gain $\mathrm{kg}^{-1}$ of total DM intake) and $\mathrm{ME}$ conversion ratio (kg BW gain $\mathrm{kg}^{-1}$ of total ME intake) were calculated. Metabolisable energy concentration of whole milk was calculated using NRC (2001) equations as $\mathrm{ME}\left(\mathrm{MJ} \mathrm{kg}^{-1}\right)=3.77(\mid 0.057$ $\times \mathrm{CP} \%)+(0.092 \times$ Fat $\%)+(0.0395 \times$ Lactose \%) $)$ and predicted ADG calculated based on equations of energy requirements for calves fed milk (NRC, 2001). At $7,21,28,42$, and $56 \mathrm{~d}$ of age in the morning after milk feeding, blood was collected via the jugular vein from randomly selected calves in both groups (8 in $\mathrm{Me} 0$ and 9 from Me14 groups) by venipuncture for analysis of $\beta$-hydroxybutyrate (BHBA). Blood was collected in 10 $\mathrm{mL}$ tubes containing sodium heparin. Two $\mathrm{mL}$ of blood samples were then transferred to two clean test tubes in duplicate. Cold $30 \%$ perchloric acid was added at $1: 1$ ratio to the blood samples for the precipitation of protein. After thorough mixing, the precipitated protein was removed by centrifuging in a refrigerated $\left(4^{\circ} \mathrm{C}\right)$ centrifuge at $2000 \mathrm{rpm}$, for $20 \mathrm{~min}$. The clear supernatant was transferred to clean glass tubes and recapped with clean screw caps, as quickly as possible, to prevent evaporation of acetone. After, it was stored at $-20{ }^{\circ} \mathrm{C}$ until analyses of BHBA. The BHBA analysis was performed through an enzymatic analysis (Williamson et al., 1962). At weaning, calves in both groups continued on the starter feed and remained in individual pens until $70 \mathrm{~d}$ of age when the experiment concluded.

\section{Statistical analysis}

Data were analysed as repeated measures for two periods (pre- and post-weaning) using the PROC MIXED model of SAS (Statistical Analysis System, version 9.2). Response variables were pooled by week for the analysis. The statistical model included calf as a random effect, and experimental group and its interaction with time as a fixed effect. The model was subjected to an autoregressive order one-covariance structure. The statistical model used was

$\mathrm{Y}_{\mathrm{cgt}}=\mu+\alpha_{\mathrm{g}}+\beta_{\mathrm{t}}+\mathrm{l}_{\mathrm{gt}}+\tau_{\mathrm{cg}}+\mathrm{e}_{\mathrm{cgt}}$ where $\mathrm{Y}_{\text {cgt }}=$ an observation value for response variables measured from calf $\mathrm{c}$ from group $\mathrm{g}$ at time $\mathrm{t} ; \mu=$ overall mean for the population; $\alpha_{g}=$ fixed effect of group $g$, where $g=$ group Meg0 or Meg14; $\beta_{t}=$ fixed effect of time $\mathrm{t} ; \mathrm{r}_{\mathrm{gt}}=$ fixed interaction of effect of group $\mathrm{g}$ and time $t ; \tau_{\mathrm{cg}}=$ random effect of calf c nested within group $g_{\text {; }}$ and $\mathrm{e}_{\mathrm{cgt}}=$ error associated with the measurement taken from calf $\mathrm{c}$ from group $\mathrm{g}$ at time $\mathrm{t}$.

Significance was declared at $p<0.05$ and tendencies at $p<0.10$. A linear mixed-effect model was also performed to compare predicted and observed ADG within groups.

\section{Results and Discussion}

\section{Intake, growth and efficiency}

Least squares means for average daily intakes, BW and ADG for both the pre-weaning period and two weeks after weaning are presented in Table 1. All calves had free access to milk during feeding time, but Meg14 calves consumed less milk ( $p=0.010)$ than Meg0 calves did. The range of milk consumption for both groups was comparable to $8.1 \mathrm{~kg} \mathrm{~d}^{-1}$ reported by Borderas et al. (2009), but lower than 8.79 and $8.97 \mathrm{~kg} \mathrm{~d}^{-1}$ reported by Jasper and Weary (2002) and Moallem et al. (2010), respectively.

All calves had low starter DMI during pre-weaning due to increased milk supply and associated increase in nutrient availability (Appleby et al., 2001; Cowles et al., 2006; Hill et al., 2008). Dosed calves consumed more $(p=0.001)$ starter DMI than Meg0 calves did, but total DMI (calf starter + milk) and estimated ME intake were not different between treatments $(p=0.358$ and $p=$ 0.153 ; respectively).

Starter DMI for control calves $\left(0.10 \mathrm{~kg} \mathrm{~d}^{-1}\right)$ was close to $0.09 \mathrm{~kg} \mathrm{~d}^{-1}$ reported by Jasper and Weary (2002) for calves fed whole milk ad libitum. Greater early starter intake by Meg14 calves could be adequate to initiate rumen function development and stimulate starter intake in the later age (Górka et al., 2011; Muya et al., 2015). These Meg14 calves consumed an average of 0.14 $\pm 0.011 \mathrm{~kg} \mathrm{~d}^{-1}$ starter DM during the pre-weaning period, representing $40 \%$ more starter feed than control calves did. This may be attributed to more developed rumen papillae and associated improved digestion and increased absorption capacity of nutrients (Kristensen et al., 2007; Górka et al., 2011) allowing high intake of solid feed by these dosed calves when milk was not available. These calves reached $0.225 \mathrm{~kg} \mathrm{~d}^{-1}$ of starter DMI during week 6 (Table 2) when milk intake was $9 \mathrm{~kg} \mathrm{~d}^{-1}$.

When compared to calf starter DMI within weeks and before weaning, the treatment difference occurred during week 7 and 8 , when dosing $M$. elsdenii NCIMB 41125 increased DMI compared to Control calves $(p=$ 0.002 and $p<0.001$, respectively). This was indicated by the significant $(p=0.005)$ interaction between treatment and time (Table 2). After weaning, dosed calves 
tended $(p=0.07)$ to consume more and consumed more $(p=0.01)$ starter DM during week 9 and 10, respectively. Pre-weaning average daily gain did not differ $(p$ $=0.261$ ) between treatments, but Meg14 calves were $5.8 \mathrm{~kg}$ heavier $(p=0.01)$ at weaning compared to Meg0 calves. Feed efficiency was greater for Meg14 calves compared to Meg0 calves $(p=0.029)$. Post-weaning DMI and estimated ME intake were greater $(p<0.05)$ for Me14 calves compared to Meg0 calves and Meg14 calves gained $0.37 \mathrm{~kg}$ more per day than Meg0 $(p=0.02)$

Table 1 - Least square means of intake, growth and efficiency of calves dosed (Meg14) or not (Meg0) with M. elsdenii NCIMB 41125.

\begin{tabular}{|c|c|c|c|c|c|c|}
\hline & \multicolumn{2}{|c|}{ Treatment* } & \multirow{2}{*}{ SEM $^{1}$} & \multicolumn{3}{|c|}{$p$-value * * } \\
\hline & Meg0 & Meg14 & & $\mathrm{T}$ & Time & $\mathrm{T} \times \mathrm{Tir}$ \\
\hline \multicolumn{7}{|l|}{ Pre-weaning } \\
\hline Milk intake, $\mathrm{kg} \mathrm{d}^{-1}$ & 8.2 & 7.4 & 0.211 & 0.010 & $<0.0001$ & 0.4437 \\
\hline Starter DMl, $\mathrm{kg} \mathrm{d}^{-1}$ & 0.10 & 0.14 & 0.011 & 0.001 & $<0.0001$ & 0.0048 \\
\hline Tot DN & 1.12 & 1.06 & 0.026 & 0.358 & 01 & 0.7116 \\
\hline ME in & 22.9 & 21.3 & 0. & 0.143 & $<0.0001$ & 0.6634 \\
\hline Initia & 34.3 & 34.8 & & 0.820 & . & - \\
\hline Wea & 69.7 & 75.5 & 2 & 0.012 & - & \\
\hline$A D G$, & 0 & 0.73 & 0.0 & 0.261 & $<0$ & 0.5719 \\
\hline Gain:F & 0.57 & 0.69 & 0.023 & 0.029 & $<0$ & 0.2955 \\
\hline \multicolumn{7}{|l|}{ Post-weaning period } \\
\hline Starter DMI, $\mathrm{kg} \mathrm{d}^{-1}$ & 1.46 & 1.73 & 0.0 & 0.027 & 01 & 0.594 \\
\hline ME int & 19.5 & 23.0 & 0.310 & 0.023 & $<0.0001$ & 0.594 \\
\hline Final BW. & 77.4 & 89.9 & 2.012 & $<0.0001$ & - & - \\
\hline$A D G$, & & 1.03 & 0.123 & 0.002 & 0.048 & 0.2613 \\
\hline Gain:Feed & 0.37 & 0.60 & 0.120 & 0.068 & 0.6060 & 0.1958 \\
\hline
\end{tabular}

${ }^{*} \mathrm{Meg} 0=$ control group, which did not receive M. elsdenii; Meg14 = received a $50-\mathrm{mL}$ oral dose of $M$. elsdenii NCIMB $41125\left(10^{8} \mathrm{~mL}^{-1}\right)$ at $14 \mathrm{~d}$ of age; * *T = Effect of treatment (dosing or not with $M$. elsdeni); $\mathrm{T} \times$ Time $=$ Interaction treatment $\times$ time; SEM $=$ Standard error of mean; Tot DMI $=$ Starter DM + Milk DM; ME intake: (Starter ME $\times$ Starter DMI) $+($ Milk ME $\times$ Milk intake); ADG $=$ Average daily gain calculated from weekly ADG.

Table 2 - Least square mean of weekly starter dry matter intake of calves dosed (Meg14) or not (Meg0) with M. elsdenii NCIMB 41125.

\begin{tabular}{|c|c|c|c|c|}
\hline & \multicolumn{2}{|c|}{ Treatment* } & \multirow{2}{*}{ SEM $^{1}$} & \multirow{2}{*}{$p$-value } \\
\hline & Meg0 & Meg14 & & \\
\hline Week 1 & 0.017 & 0.013 & 0.0029 & 0.915 \\
\hline Week 2 & 0.033 & 0.030 & 0.0460 & 0.937 \\
\hline Week 3 & 0.056 & 0.061 & 0.0063 & 0.874 \\
\hline Week 4 & 0.066 & 0.071 & 0.0069 & 0.903 \\
\hline Week 5 & 0.079 & 0.098 & 0.0098 & 0.526 \\
\hline Week 6 & 0.104 & 0.137 & 0.0104 & 0.161 \\
\hline Week 7 & 0.117 & 0.225 & 0.0234 & 0.002 \\
\hline Week 8 & 0.354 & 0.513 & 0.0456 & $<0.001$ \\
\hline Week 9 & 1.150 & 1.371 & 0.0624 & 0.071 \\
\hline Week 10 & 1.781 & 2.092 & 0.0668 & 0.012 \\
\hline
\end{tabular}

calves did and weighed $11.6 \mathrm{~kg}$ more than $\mathrm{Meg} 0$ calves at the end of the study.

The progressive change in milk and starter DMI over time are shown in Figures 1 and 2 respectively. In agreement with previous studies, all calves increased milk consumption during the first two weeks and were able to consume a large quantity of milk (De Passillé et al., 1992; Khan et al., 2007). There was fluctuation of milk intake throughout the pre-weaning period in both groups, with the average milk intake increasing with age. Starter DMI was very low in both treatments, but exponentially increased from day 52 to 70 . This was related to milk withdrawal, as it was reduced to $4 \mathrm{~L}$ once in the morning until weaning at 56 days old. Differences between treatments in starter feed intake became apparent at week 7 .

The average daily weight gain did not differ $(p=$ 0.261 ) between treatments during the pre-weaning pe-

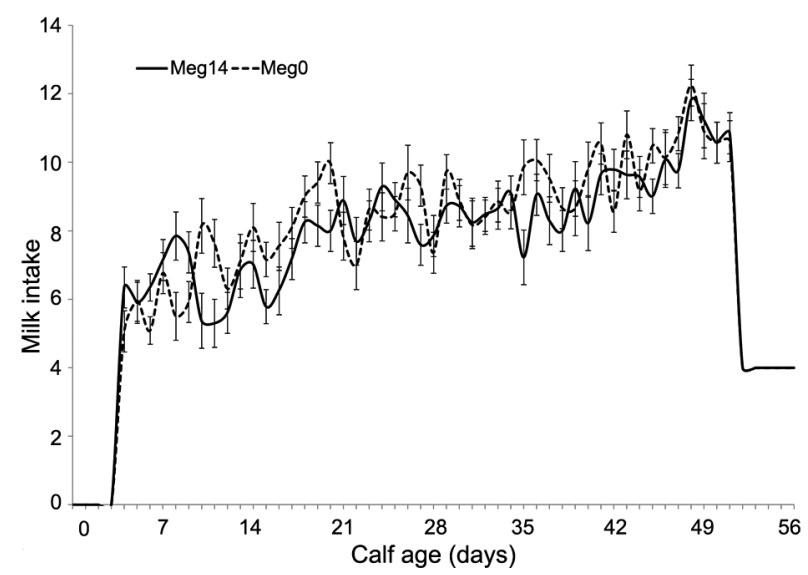

Figure 1 -Milk intake $( \pm \mathrm{SE})\left(\mathrm{kg} \mathrm{d}^{-1}\right)$ over period for calves dosed (Meg14) or not (Meg0) with M. elsdenii NCIMB 41125 on day 14 of age.

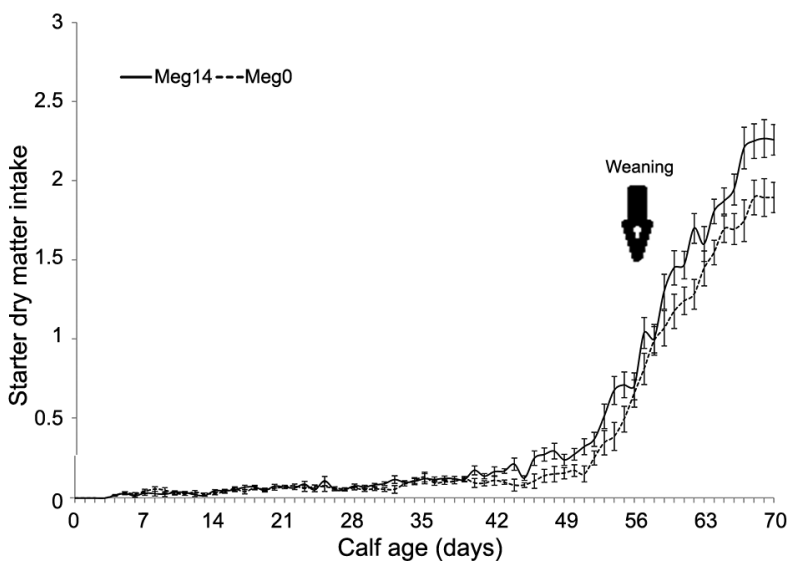

Figure 2 - Starter dry matter intake $( \pm \mathrm{SE})\left(\mathrm{kg} \mathrm{d}^{-1}\right)$ over period for calves dosed (Meg14) or not (Meg0) with M. elsdenii NCIMB 41125 on day 14 of age. 
riod, but it was higher $(p=0.002)$ in the Meg14 group during post-weaning (week 9 and 10). From d 21 to d 42, Meg0-calves increased their ADG from 0.51 to $1.0 \mathrm{~kg} \mathrm{~d}^{-1}$ (Figure 3), while Me14-calves increased it from 0.51 to $1.2 \mathrm{~kg} \mathrm{~d}^{-1}$ during the same period. In both groups, ADG decreased at weaning to less than $0.4 \mathrm{~kg} \mathrm{~d}^{-1}$. Pre-weaning gain: feed was greater $(p<0.029)$ for Meg0 compared to Meg14, but tended $(p<0.068)$ to be greater for Meg14 post-weaning compared to Meg0. The increased post-weaning ADG within and between treatments provided a net growth advantage to Meg14 calves.

The decrease in ADG around weaning reported in previous studies (Bar-Peled et al., 1997; Jasper and Weary, 2002; Cowles et al., 2006; Terré et al., 2006) in calves fed high volumes of milk was also found in this study, as all calves decreased ADG a week before weaning. This is explained by the decrease in energy and protein intake when milk allowance was reduced. However, Meg0 calves presented a more pronounced decrease compared with Meg14 calves. A common pitfall encountered in high milk feeding programs is the low starter intake at weaning (Bar-Peled et al., 1997; Brown et al., 2005; Cowles et al., 2006). Conversely, increased starter feed in Meg14 group provided the calves a growth advantage after weaning as reflected in the high post-weaning ADG, suggesting improved intake of energy when calves were weaned from milk, as starter was the only source of energy available. This suggests that dosing M. elsdenii could be an efficient strategy for weaning calves adequately when fed larger volumes of milk or milk replacer. This may be attributed to a residual effect of early increased starter DMI and, therefore, increased gut fill. Early starter consumption increases nutrient digestibility, and consequently improves ruminal microbiota and fermentation activities (Anderson et al., 1987).

Dosed calves in the current study, gained $100 \mathrm{~g} \mathrm{~d}^{-1}$ and were $5 \mathrm{~kg}$ heavier than control calves at weaning at $56 \mathrm{~d}$. The higher starter DMI was more pronounced during the last two weeks prior weaning, and was 108

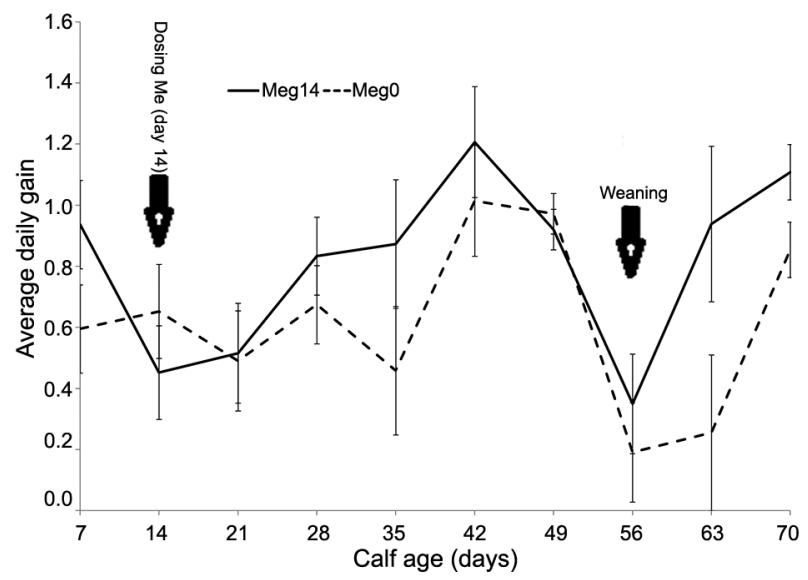

Figure 3 - Average daily gain $( \pm \mathrm{SE})\left(\mathrm{kg} \mathrm{d}^{-1}\right)$ over period for calves dosed (Meg14) or not (Meg0) with M. elsdenii. and $159 \mathrm{~g} \mathrm{~d}^{-1}$ during week 7 and 8, respectively, when milk intake was similar between the two groups. The improved consumption of solid feed of calves dosed with M. elsdenii, and possibly related ruminal activity have mitigated negative effects of ad libitum milk intake and lessened the negative transitional effects of milk removal on growth and performance.

The average daily gain of pre-weaned calves was compared with predicted ADG (NRC, 2001) within groups to ascertain the efficiency of nutrient utilization, and results are presented in Figure 4. In Meg14 group, observed ADG was higher $(p<0.001)$ than predicted ADG, whereas in Meg0 group, observed ADG did not differ from the model $(p=0.721)$. Greater actual preweaned ADG observed in Meg14 group than predicted by the NRC (2001) model may indicate more efficient use of starter nutrients by calves that received $M$. elsdenii, supporting high ME intake and weaning BW observed in this group. This is related to improved starter DMI observed in Meg14-calves. They consumed more starter than Meg0 calves did, and therefore were more adapted to dry feed intake, suggesting improved absorptive capacity (Coverdale et al., 2004). This is believed to be the result of increased ruminal butyrate, which provides energy to thicken the rumen wall, form papillae, and increase capillary development (Weigand et al., 1975).

\section{Blood beta-hydroxybutyrate}

Results of effects on plasma BHBA concentration are presented in Table 3 and Figure 5. On d 7 (prior to treatment administration), BHBA concentrations tended $(p=0.09)$ to be greater for Meg0 calves compared to Meg14 calves; however, BHBA concentration increased

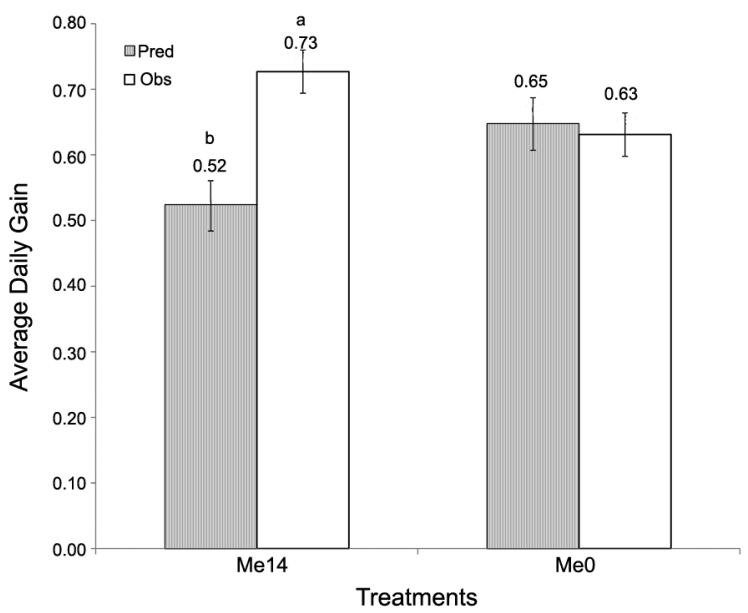

Figure 4 - Comparison of observed and predicted average daily gain ( $k g \mathrm{~d}^{-1}$ ), using equation based on metabolisable energy requirement (NRC, 2001) during the pre-weaning period of calves dosed (Meg14) or not (Meg0) with M. elsdenii; abLeast square means differ significantly between treatment groups at the same time point $(p<0.01)$. 
Table 3 - Least square mean of plasma beta-hydroxybutyrate (BHBA) of calves dosed (Meg14) or not (Meg0) with M. elsdenii NCIMB 41125.

\begin{tabular}{|c|c|c|c|c|c|}
\hline & \multicolumn{2}{|c|}{ Treatment $^{*}$} & \multirow{2}{*}{$\mathrm{SEM}^{1}$} & \multicolumn{2}{|l|}{$p$-value ** } \\
\hline & Meg0 & Meg14 & & Time & $\mathrm{T} \times$ Time \\
\hline \multicolumn{6}{|l|}{$\mathrm{BHBA}^{2}, \mathrm{mmol} \mathrm{L}^{-1}$} \\
\hline On day 7 (before dosing) & 0.076 & 0.057 & 0.0380 .093 & - & - \\
\hline Average after dosing) & 0.106 & 0.281 & 0.0570 .034 & $<0.0001$ & 0.009 \\
\hline \multicolumn{6}{|c|}{$\begin{array}{l}{ }^{*} \text { Meg0 = control group, which did not receive } M \text {. elsdenii; Meg14 = received } \\
\text { a } 50 \text {-mL oral dose of } M \text {. elsdenii NCIMB } 41125\left(10^{8} \mathrm{CFU} \mathrm{mL}^{-1}\right) \text { at } 14 \mathrm{~d} \text { of } \\
\text { age; }{ }^{* *} \mathrm{~T}=\text { Effect of treatment (dosing or not with } M \text {. elsdeni); } \mathrm{T} \times \text { Time }= \\
\text { Interaction treatment } \times \text { time; }{ }^{1} \mathrm{SEM}=\text { Standard error of mean; }{ }^{2} \mathrm{BHBA}=\text { beta- } \\
\text { hydroxybutyrate. }\end{array}$} \\
\hline
\end{tabular}

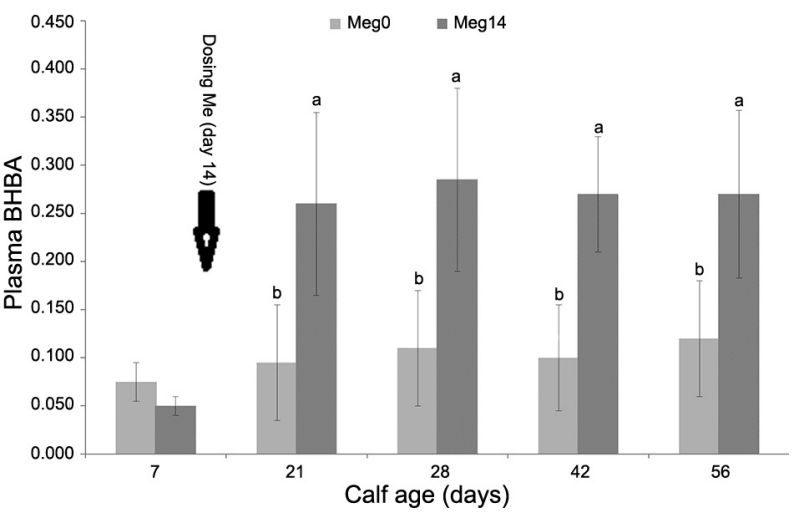

Figure 5 - Plasma beta-hydroxybutyrate (BHBA) $\left(\mathrm{mmol} \mathrm{L}^{-1}\right)$ of calves dosed (Meg14) or not (Meg0) with $M$ elsdenii; abLeast square means differ significantly between treatment groups at the same time point $(p<0.01)$.

drastically in Meg14 from d 21 and until d 56 ( $p=0.03)$. The potential of $M$. elsdenii to increase the proportion of rumen propionate and butyrate was previously reported (Marounek et al., 1989; Cruz et al., 2001; Henning et al., 2010; Muya et al., 2015). The particular role of these two VFA on stimulating rumen epithelial cells and papillae development and thereby, increasing the capacity of solid feed intake, has been previously discussed (Tamate et al., 1962; Coverdale et al., 2004; Lane and Jesse, 1997). The effects of VFA are reported to be most likely associated with the rate at which they are metabolized by mucosal cells during absorption, being over $90 \%$ of butyric acid and approximately $50 \%$ of propionic acid metabolized and oxidized to ketone bodies (Britton and Krehbiel, 1993). As it is oxidized by the rumen epithelial cells and passes through the rumen wall, butyric acid is converted to BHBA (Quigley, 1991; Lesmeister and Heinrichs, 2004), which is used as an indicator of the rumen development (Suarez et al., 2006).

Dosing $M$. elsdenii could have positive effects on rumen papillae development and function, as previously showed in calves (Kristensen et al., 2007; Górka et al., 2011), through increased rumen butyrate (Muya et al., 2015) and, thus, improve calves intake and growth. The increase rumen butyrate could have allowed for continu- ous exposition of rumen epithelial cells to its preferred energy source, and consequently stimulated rumen development. The more developed calf rumen observed in conventional rearing systems, compared to accelerated growth, is explained by higher ruminal butyrate concentration (Lesmeister and Heinrichs, 2004).

In the study of Muya et al. (2015), calves fed restricted milk and dosed with $M$. elsdenii had greater reticulum-rumen weight and papillae density, with greater papillae width compared to control calves. These improvements were associated with greater ruminal butyrate concentration and plasma BHBA. In this study, plasma BHBA concentration of dosed calves increased the week after it was dosed with $M$. elsdenii, when they consumed more calf starters feed than control calves did from two weeks before weaning until the end of the experimental period and kept their growth advantage after weaning.

\section{Conclusion}

Administering Megasphaera elsdenii NCIMB 41125 to Holstein calves at $14 \mathrm{~d}$ of age in accelerated growth program improved pre-and post-weaning performance, starter feed intake and feed efficiency. In addition, greater plasma BHBA concentration in these calves may be an indicative of prompt rumen physical development with concomitant increased metabolic activity of the rumen epithelium.

\section{Acknowledgment}

This research was supported by the Agricultural Research Council, Animal Production Institute, South Africa, which is gratefully acknowledged.

\section{References}

Anderson, K.L.; Nagaraja, T.G.; Morrill, J.L.; Avery, T.B.; Galitzer, S.J.; Boyer, J.E. 1987. Ruminal microbial development in conventionally or early-weaned calves. Journal of Animal Science 64: 1215-1226.

Appleby, M.C.; Weary, D.M.; Chua, B. 2001. Performance and feeding behavior of calves on ad libitum milk from artificial teats. Apply Animal Behaviour Science 74: 191-201.

Baldwin, R.L.; McLeod, K.R.; Klotz, J.L.; Heitmann, R.N. 2004. Rumen development, intestinal growth and hepatic metabolism in the pre- and post-weaning ruminant. Journal of Dairy Science 87 (E Suppl): E55-E65.

Bar-Peled, U.; Robinzon, B.; Maltz, E.; Tagari, H.; Folman, Y.; Bruckental, I; Voet, H.; Gacitua, H.; Lehrer, A.R. 1997. Increased weight gain and effects on production parameters of Holstein heifer calves that were allowed to suckle from birth to six weeks of age. Journal of Dairy Science 80: 2523-2528.

Borderas, T.F.; De Passillé, A.M.B.; Rushen, J. 2009. Feeding behavior of calves fed small or large amounts of milk. Journal of Dairy Science 92: 2843-2852.

Britton, R.; Krehbiel, C. 1993. Nutrient metabolism by gut tissue. Journal of Dairy Science 76: 2125-2131 
Brown, E.G.; VandeHaar, M.J.; Daniels, K.M.; Liesman, J.S.; Chapin, L.T.; Keisler, D.H.; Weber Nielsen, M.S. 2005. Effect of increasing energy and protein intake on body growth and carcass composition of heifer calves. Journal of Dairy Science 88: $585-594$

Coverdale, J.A.; Tyler, H.D.; Quigle, J.D.; Brumm, J.A. 2004. Effect of various levels of forage and form of diet on rumen development and growth in calves. Journal of Dairy Science 87: 2554-2562.

Cowles, K.E.; White, R.A.; Whitehouse, N.L.; Erickson, P.S. 2006. Growth characteristics of calves fed an intensified milk replacer replacer regimen with additional lactoferrin. Journal of Dairy Science 89: 4835- 4845.

Cruz, O.S.; Rivera, C.R; Castañeda, G.S. 2001. Stimulation of the Megasphaera elsdenii's butyrate production in continuous culture by a yeast additive. Brazilian Archives of Biology and Technology 44: 2-9.

De Passillé, A.M.B.; Metz, J.H.M.; Wiepkema, P.R. 1992. Does drinking milk stimulate sucking in young calves? Applied Animal Behaviour Science 34: 23-36.

Górka, P.; Kowalski, Z.M.; Pietrzak, P.; Kotunia, A.; Kilijanczyk, R.; Flaga, J.; Holst, J.J.; Guilloteau, P; Zabielski, R. 2009. Effect of sodium butyrate supplementation in milk replacer and starter diet on rumen development in calves. Journal of Physiology and Pharmacology 60: 47-53.

Górka, P.; Kowalski, Z.M.; Pietrzak, P.; Kotunia, A.; Jagusiak, W.; Holst, J.J.; Guilloteau, P.; Zabielski, R. 2011. Effect of method of delivery of sodium butyrate on rumen development in newborn calves. Journal of Dairy Science 94: 5578-5588.

Hammon, H.M.; Schiessler, G.; Nussbaum, A.; Blum, J.W. 2002. Feed intake patterns, growth performance, and metabolic and endocrine traits in calves fed unlimited amounts of colostrum and milk by automate, starting in the neonatal period. Journal of Dairy Science 85: 3352-3362.

Henning, P.H.; Horn, C.H.; Steyn, D.G.; Meissner, H.H. 2010. The potential of Megasphaera elsdenii isolates to control ruminal acidosis. Animal Feed Science and Technology 157: 13-19.

Hill, S.R.; Knowlton, K.F.; Daniels, K.M.; James, R.E.; Pearson, R.E.; Capuco, A.V. 2008. Effects of milk replacer composition on growth, body composition, and nutrient excretion in preweaned Holstein heifers. Journal of Dairy Science 91: 3145-3155.

Jasper, J.; Weary, D.M. 2002. Effects of ad libitum milk intake on dairy calves. Journal of Dairy Science 85: 3054-3058.

Khan, M.A.; Lee, H.J.; Lee, W.S.; Kim, H.S.; Kim, S.B.; Ki, K.S.; Ha, J.K.; Lee, H.G.; Choi, Y.J. 2007. Pre- and postweaning performance of Holstein female calves fed milk through stepdown and conventional methods. Journal of Dairy Science 90: 876-885.

Kristensen, N.B.; Sehested, J.; Jensen, S.K.; Vestergaard. M. 2007. Effect of milk allowance on concentrate intake, ruminal environment, and ruminal development in milk-fed Holstein calves. Journal of Dairy Science 90: 4346-4355.
Lane, M.A.; Jesse, B.W. 1997. Effect of volatile fatty acid infusion on development of the rumen epithelium in neonatal sheep. Journal of Dairy Science 80: 740-746.

Lesmeister, K.E.; Heinrichs, A.J. 2004. Effects of corn processing on growth characteristics, rumen development, and rumen parameters in neonatal dairy calves. Journal of Dairy Science 87: 3439-3450.

Marounek, M.; Fliegerova, K.; Bartos, S. 1989. Metabolism and some characteristics of ruminal strains of Megasphaera elsdenii. Applied and Environmental Microbiology 55: 15701573.

Moallem, V.; Werner, D.; Lehrer, H.; Zachut, M.; Liushits, L.; Yakoby, S.; Shamay, A. 2010. Long-term effects of ad libitum whole milk prior to weaning and prepubertal protein supplementation on skeletal growth rate and first lactation milk production. Journal of Dairy Science 93: 2639-2650.

Muya, M.C.; Nherera, F.V.; Miller, K.A.; Aperce, C.C.; Moshidi P.M.; Erasmus. L.J. 2015. Effect of Megasphaera elsdenii NCIMB 41125 dosing on rumen development, volatile fatty acid production and blood $\beta$-hydroxybutyrate in neonatal dairy calves. Journal of Animal Physiology and Animal Nutrition 99: 913-918. DOI: 10.1111/jpn.12306.

National Research Council [NRC]. 2001. Nutrient Requirements of Dairy Cattle. 7ed. National Academy of Science, Washington, DC, USA.

Quigley, J.D.; Caldwell, L.A.; Sinks, G.D.; Heitmann, R.N. 1991. Changes in blood glucose, nonesterified fatty acids, and ketones in response to weaning and feed intake in young calves. Journal of Dairy Science 74: 250-257.

Suarez, B.J.; Van Reenen, C.G.; Gerrits, W.J.J.; Stockhofe, N.A.; Van Vuuren, M.; Dijkstra, J. 2006. Effects of supplementing concentrates differing in carbohydrate composition in veal calf diets. II. Rumen development. Journal of Dairy Science 89: 4376-386.

Tamate, H.; McGilliard, A.D.; Jacobson, N.L.; Getty, R. 1962. Effect of various dietaries on the anatomical development of the stomach in the calf. Journal of Dairy Science 45: 408-420.

Terré, M.; Devant, M.; Bach, A. 2006. Effect of level of milk replacer fed to Holstein calves on performance during the preweaning period and starter digestibility at weaning. Livestock Science 110: 82-88.

Weigand, E.; Young, J.W.; McGilliard, A.D. 1975. Volatile fatty acid metabolism by rumen mucosa from cattle fed hay or grain. Journal of Dairy Science 58: 1294-1300.

Williamson, D.H; Mellanby, J.; Krebs, H.A. 1962. Enzymic determination of Dbetahydroxybutiric acid and aceto-acetic acid in blood. Biochemistry Journal 82: 90-96. 